\title{
SIMO Haberleşme Kanallarında Enerji Tabanlı İşbirlikli Spektrum Algilama"
}

\author{
Fatih Yavuz Ilgin ${ }^{1 *}$ \\ ${ }^{1}$ Erzincan Binali YILDIRIM Üniversitesi, Mühendislik Fakültesi, Elektrik Elektronik Müh. Bölümü, Erzincan, Türkiye (ORCID: 0000-0002-7449-4811)
}

(Konferans Tarihi: 5-7 Mart 2020)

(DOI: 10.31590/ejosat.araconf13)

ATIF/REFERENCE: Ilgın, F. Y. (2020) SIMO Haberleşme Kanallarında İşbirlikli Spektrum Algılama, Avrupa Bilim ve Teknoloji Dergisi, (Özel say1), 96-104.

$\ddot{O} \mathbf{z}$

Son yıllarda haberleşme sistemlerinde yaşanan hızlı gelişim süreci, kablosuz haberleşme uygulamalarının sayısını oldukça artırmış durumdadır. Kablosuz haberleşme sistemlerinde gerçekleşen bu gelişim, beraberinde spektrumda daha fazla band genişliği ihtiyacını da gerektirmektedir. Band genişliği talebinin artışı ise spektrum kıtlığı problemini gün yüzüne çıkarmıştır. Spektrum kitlığı problemini aşmak için en geçerli yol, sabit frekans tahsisi yerine firsatçı spektrum kullanımına geçilmesidir. Spektrumu firsatçı kullanarak dinamik spektrum atama yöntemlerini uygulamak ise Bilişsel Radyo sistemlerinin temel amacıdır. Bilişsel Radyo bulunduğu spektrum ortamını algılayarak boş spektrum bölgelerini belirleyerek bu bölgeleri ikincil kullanıcıların erişimine açmaktadır. Ikincil kullanıcı spektrum kullanımı için belirli bir ücret ödemeyen veya bir spektrum bölgesini yasal olarak kullanma hakkına sahip olmayan kişidir. Aynı şekilde lisanslı kulanıcı ise belirli bir spektrum bölgesini yasal olarak kullanma hakkına sahip kişi olarak tanımlanmaktadır. Bu tanımlar doğrultusunda yapılan bu çalışmada Bilişsel Radyo sistemleri için spektrum algılama yöntemlerinden biri olan, Enerji Tabanlı Spektrum Algılama için, adaptif bir spektrum algılama yöntemi önerilmiştir. Ayrıca önerilen yöntemde gürülttü seviyesinin tahmini için farklı bir kestirim yöntemi önerilmektedir. Bilindiği üzere enerji tabanlı algılama yöntemlerinin en büyük dezavantajı gürültü belirsizliği faktörünün algılama performansı üzerinde oluşturduğu olumsuz etkidir. Bu olumsuz etkiyi azaltmak için önerilen yöntemde ortamda bulunan gürültü, Marhenko Pastur teoremi ile tahmin edilerek, eşik değeri adaptif şekilde değiştirilmektedir. Önerilen yöntemin Rayleigh sönümlemeli tek giriş- çok çıkışlı sistemlerde benzetim çalışmaları yapılmıştır. Benzetim çalışmaları işbirlikli ve işbirliksiz algılama yöntemleri için farklı gürültü seviyeleri için incelenmiştir. Ayrıca benzetim sonuçlarında algılama teorisi çalışmaları için sıklıkla kullanılan ROC eğrilerine de yer verilmektedir. Böylece önerilen algılama yönteminde geleneksel enerji algılama yöntemine göre olumlu sonuçlar gözlemlenmiştir.

\section{Energy-Based Cooperative Spectrum Sensing In SIMO Communication Channels}

\begin{abstract}
The rapid development process in communication systems in recent years has increased the number of wireless communication applications considerably. This development in wireless communication systems requires the need for more bandwidth in the spectrum. The increase in bandwidth demand brought up the problem of spectrum shortage. The most valid way to overcome the
\end{abstract}

\footnotetext{
* Sorumlu Yazar: Erzincan Binali YILDIRIM Üniversitesi, Mühendislik Fakültesi, Elektrik Elektronik Müh. Bölümü, Erzincan, Türkiye, fyilgin@erzincan.edu.tr (ORCID: 0000-0002-7449-4811)
}

** Bu makale International Conference on Access to Recent Advances in Engineering and Digitalization (ARACONF 2020) de sunulmuştur. 
problem of spectrum shortage is to switch to the use of opportunistic spectrum instead of fixed frequency allocation. Using spectrum opportunistically is the main purpose of Cognitive Radio systems. Cognitive Radio detects the spectrum environment in which it is located and determines the empty spectrum regions and makes these regions accessible to secondary users. The secondary user is the person who does not pay a specific fee for the use of the spectrum or does not have the legal right to use a spectrum region. Similarly, the licensed user is defined as the person who has the legal right to use a certain spectrum region. An adaptive spectrum sensing method for Energy Based Spectrum Sensing, which is one of the spectrum sensing methods for Cognitive Radio systems, is proposed in this study conducted in line with these definitions. In addition, a different estimation method is proposed for the estimation of the noise level in the proposed method. As it is known, the biggest disadvantage of energy based sensing methods is the negative effect of noise uncertainty factor on sensing performance. In the proposed method to reduce this negative effect, the noise in the environment is estimated by Marhenko Pastur theorem and the threshold value is adaptively changed. Simulation studies of single-multi-output systems with Rayleigh damping are proposed. Simulation studies have been studied for different noise levels for cooperative and noncooperative detection methods. Also included in the simulation results are ROC curves that are frequently used for detection theory studies. Thus, positive results were observed in the proposed perception method compared to traditional energy perception method.

Keywords: Cognitive Radio, Energy Based Sensing, Marchenko Pastur Theorem, Cooperative Detection, Spectrum Efficiency.

\section{Giriş}

Günümüzde kablosuz haberleşme uygulamaları giderek daha fazla band genişliği ve iletim hızına ihtiyaç duymaktadır. Bu durumun sonucu olarak radyo frekans spektrumunda haberleşme sistemleri için yeterli alan bulunması, problem olmaya başlamaktadır(Erpek, Steadman, \& Jones, 2007). Özellikle gelecek 10 y1lda spektrum kıtlığı probleminin çok yüksek boyutlara erişeceği tahmin edilmektedir(Dahlman, Parkvall, \& Skold, 2013). Bu nedenle radyo frekans spektrumunu daha verimli kullanılması zorunluluğu bulunmaktadır. Bazı bölgelerde yapılan ölçümlerde spektrumun verimsiz kullanıldığını ortaya koymaktadır. Temel olarak bu verimsizliğin temel nedeni sabit frekans atama yöntemleridir(Mitola \& Maguire, 2001). Bu yöntemler gereği radyo frekans spektrumunun bir bölgesi, belirli bir kullanıcıya(lisanslı kullanıcı) tahsis edilmektedir. Böylece lisanslı kullanıcı bu spektrum bölgesini kullanmadığı zamanlar, bu bölge atıl durumda kalmaktadır(De Vito, 2013). Lisanslı kullanıcı belirli bir spektrum bölgesini yasal olarak kullanma hakkına sahip olan kişi olarak tanımlanmaktadır. İstenmeyen bu durumu önlemek için geliştirilen teknolojilerden biri Bilişsel Radyo (BR) sistemleridir(Ayse Kortun, Ratnarajah, Sellathurai, Liang, \& Zeng, 2014). BR sistemleri radyo frekans spektrumunu sürekli tarayarak boş spektrum bölgelerini bulmaktadır. Bu bölgelerde kullanıcı değişikliği yapmaktadır(Abdalrazik, Soliman, Abdelkader, \& Abuelfadl, 2016; Mitola, 2006). Bu yöntemle lisanlı kullanıcı kendisine ayrılmış spektrum bölgesinden ayrıldığında, bu bölge lisansız başka kullanıcıların erişimine açılmaktadır ki bu tür kullanıcılara ise Bilişsel Radyo(BR) kullanıcısı ve ya lisansız kullanıcı denilmektedir(Mohammadi, Javadi, Ciuonzo, Persico, \& Pescapé, 2019). Genel olarak BR sistemlerinde spektrum ağılama algılama genişband ve darband olarak yapılmaktadır(De Vito, 2013). Genişband spektrum algılama uygulamaları spektrum verimi bakımından daha elverişlisi olsa da, lisanssız BR kullanıcılarının spektrum farklı bölgelerinde haberleşme yapabilmesi uygulama da bir takım zorluklar doğurmaktadır. Bunların en başında lisansız bir BR kullanıcısı spektrumun farklı bölgelerinde haberleşme yapabilmesi için donanımsal bir takım değişiklikler yapması gerekebilir(Commission, 2002). Örneğin anten boyu, modülasyon şekli vb. Bu nedenlerle BR sistemlerinde geniş band uygulamaları fazla tercih edilmeyebilir. Genişband uygulamalarda işaretin spektrum özellikleri ve genlik özellikleri kullanılarak yapılan çalışmalar mevcuttur(Dibal, Onwuka, Agajo, \& Alenoghena, 2018). Darband uygulamalar ise spektrum verimliliği bakımından geniş band uygulamalara göre dezavantajlı olsa da, spektrumun sadece belirli bir bölgesini algılamak hem daha az maliyetli hem de doğruluk oranı daha yüksek olması sebebiyle daha fazla kullanılmaktadır(Çiflikli \& Ilgin, 2018; Zeng \& Liang, 2009). Darband spektrum algılama yöntemleri ise alınan işaretin istatistiksel özellikleri, periyodiklik özelliği veya özdeğer dağılımı gibi parametrelerden faydalanmaktadır. Darband spektrum algılama yöntemleri kör veya yarı kör olarak ikiye ayrılmaktadır. Kör yöntemler hiçbir önsel bilgiye(modülasyon türü, gürültü varyansı vb.) ihtiyaç duymadan, spektrumda bulunan lisanslı kullanıcıların varlığını algılayabilirler(Pillay \& Xu, 2012; Yonghong Z., Ying-Chang L., \& Rui Z., 2008). Fakat (Szczerba et al., 2013)kör olmayan yöntemler de gürültü varyansının, algılanacak işaretin modülasyon bilgisi gibi bilgilerin önceden bilinmesi gerekmektedir. Kör yöntemlerin en başında özdeğer tabanlı algılama yöntemleri gösterilebilir(Edelman, 2005; He, Ratnarajah, Yousif, Xue, \& Sellathurai, 2016). Bu yöntemler alınan işaretin özdeğer farklılıklarından faydalanmaktadır. En büyük en küçük özdeğer farkı veya en büyük özdeğer- iz tabanlı algılama yöntemleri özdeğer tabanlı algılama için en yaygın kullanılan istatistiklerdir(A. Kortun, Ratnarajah, Sellathurai, Zhong, \& Papadias, 2011). Bu yöntemlerden farklı olarak yarı kör yöntemler ve çift eşikli özdeğer tabanlı algılama yöntemleri kullanılmaktadır(Charan \& Paney, 2016; Verma \& Singh, 2016). Çevrimsel durağanlık tabanlı algılama yöntemleri de BR sistemlerinde spektrum algılama için kullanılmaktadır(S \& Jayasheela, 2012). Bu yöntemler sadece Dikgen Frekans Bölüşümlü Çoğullama (Orthogonal Frequency Division Multipexing-OFDM) tabanlı işaretlere uygulanabilir(Lu, Li, Swindlehurst, Ashikhmin, \& Zhang, 2014). Enerji Algılama (EA) tabanlı algılama yöntemleri ise spektrum algılama için, hesaplama maliyetinden dolayı en fazla tercih edilen yöntemdir(Li \& Lu, 2016; Luo, Wang, Zhang, \& Guan, 2019; Shi-Qi, Bin-Jie, \& Xian-Yi, 2012). Enerji tabanlı algılama yöntemleri hem işbirliksiz hem de işbirlikli haberleşme sistemlerine uygulanabilir.

Bu çalışmada Tek Giriş Çok Çıkışlı(Single Input Multiple Output- SIMO) haberleşme sistemleri için gürültü belirsizliğinin algılama performansına olan bozucu etkilerini azaltmak için, adaptif eşik değeri kullanan bir spektrum algılama yöntemi önerilmiştir. Gürültü varyansının belirlenmesi için Marchenko-Pastur teoremi kullanılarak alınan işaretin özdeğer dağılımı hesaplanmıştır. Ayrıca yapılan benzetim çalışmaları, işbirlikli spektrum algılama için sert ve yumuşak birleştirme yöntemlerine göre benzetim çalışmaları yapılmıştır.

$\mathrm{Bu}$ çalışmanın organizasyonu şu şekildedir. Algılama modeli ve EA tabanlı spektrum algılamanın temelleri II. Bölüm’de açıklanmıştır. Bunun yanı sıra benzetim çalışmalarında da kullanılacak olan işbirlikli algılama yine bu bölümde açıklanmıştır. III. 
Bölümde ise adaptif eşik değeri belirlemek için kullanılan yöntem açıklanmıştır. Çalışmanın benzetim sonuçları ise IV. Bölümde verilmiştir.

$\mathrm{Bu}$ çalışmada kü̧̈ük normal karakterler $(x)$ vektörleri, koyu karakterler $(\mathbf{x})$ ise matrisleri ifade etmektedir.

\section{Materyal ve Metot}

\subsection{Spektrum Algılama Modeli}

Verilen bir frekans bandında gürültüye ek olarak herhangi bir haberleşme işareti(birincil kullanıcı) olup olmadığının belirlenmesi, spektrum algılama işleminin temelini oluşturmaktadır. Bu çalışmada kullanılan spektrum algılama modeli Şekil 1 ile verilmektedir.

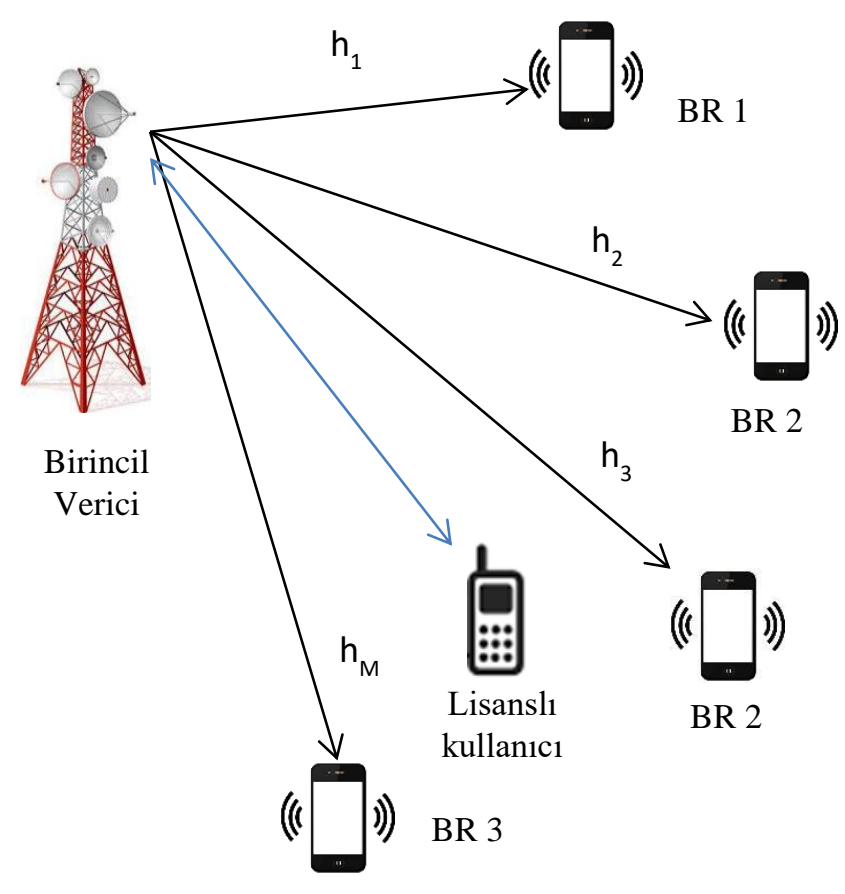

Şekil 1. SIMO sistem için spektrum algllama modeli

Burada birincil verici pasif duruma geçtiğinde, ilgili spektrum bölgesin BR kullanıcılarının erişimine açılmaktadır. Birincil verici tekrar aktif olduğunda ise BR kullanıcıları, girişim oluşmaması için bu frekans bölgesini birincil vericiye bırakmaktadır. Bu durum matematiksel olarak Eşitlik 1 ve Eşitlik 2 ile ifade edilebilir(Zeng \& Liang, 2009).

$H_{0} \rightarrow \mathbf{y}=\eta$

$$
H_{1} \rightarrow \mathbf{y}=\mathbf{s}+\eta
$$

Burada $H_{0}$ birincil vericinin pasif olduğunu yani BR kullanıcılarının bu frekans bölgesini kullanabileceğini, $H_{I}$ ise birincil vericinin aktif olduğunu belirtmektedir. $s$ birincil verici işaretini, $\eta$ ise $\left(\eta \sim N\left(0, \sigma_{\eta}^{2}\right)\right)$ şeklinde Gauss dağılımlı gürültü işaretini temsil etmektedir. $\mathbf{y}$ ise her bir BR kullanıcısı tarafından alınan işaretin matriste depolanmış şeklidir. BR kullanıcılarının algıladığı örnek sayısı $N$, sistemde bulunan BR kullanıcı sayısı ise $M$ ile gösterilirse algılama modelinde $\mathbf{y}, M x N$ boyutunda bir matris olmaktadır. Şekil 1'de verilen algılama modeli aynı zamanda çok kullanıcılı bir Tek Giriş Çok Çıkışlı(Single Input Multiple Output- SIMO) bir haberleşme kanalını da modellemektedir. Burada $h_{l}$, birinci kullanıcı ile verici arasındaki kanal katsayısını temsil etmektedir. Bu böylece her bir BR kullanıcısınınsan alınan işaret örnekleri $\mathbf{y}$ matrisinde depolanırsa, $\mathbf{y}$ matrisi aşağıdaki gibi elde edilmektedir(Dahlman et al., 2013). 
$\mathbf{y}(n)=s(n)\left[\begin{array}{c}h_{1} \\ h_{2} \\ \vdots \\ h_{M}\end{array}\right]$

Genel olarak spektrum algılamada öncelikle alınan $\mathbf{y}(n)$ işareti ile, belirlenen bir test istatistiği eşik değeri ile karşılaştırılır. Bu durum matematiksel olarak aşağıdaki gibi ifade edilmektedir(Ahmad, Yang, \& Lee, 2015).

$\begin{aligned} \text { Test Istatistiği } & >\gamma \rightarrow H_{1} \\ <\gamma & \rightarrow H_{0}\end{aligned}$

Test istatistiği spektrum algılama için kullanılacak olan yönteme göre değişmektedir. Örneğin özdeğer tabanlı algılama için alınan işaretin kovaryans matrisi özdeğerleri oranı olabildiği gibi, enerji algılama için alınan işaretin enerjisidir. EA tabanlı algılamada antenler vasıtası ile algılanan lisanslı kullanıcı işaretinin enerjisi aşağıdaki Eşitlik 5 ile hesaplanmaktadır(Li \& Lu, 2016).

$T_{E D}=\sum_{n=1}^{N}\left|\mathbf{y}_{i}[n]\right|^{2}$

Burada $T_{E D}$ ve $y_{i}[n]$ sırsıyla EA tabanlı algılama için test istatistiğini ve $i$. BR kullanıcısının algıladığı işareti belirtmektedir. Böylece belirlenen spektrum bölgesinin dolu/boş olduğu Eşitlik 6 ile verilen yöntemle karar verilmektedir.

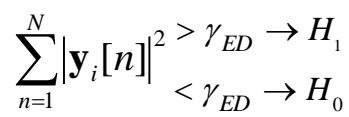

Burada $\gamma_{E D}$, EA tabanlı spektrum algılama için eşik değeridir. Teorik olarak Algılama Olasılığı $\left(P_{d}\right)$ ve Yanlış Algılama Olasılığ $\left(P_{f a}\right)$, test istatistiği değerinin istatistiksel özelliklerine göre değişiklik göstermektedir. $\mathrm{BR}$ sistemleri ve radar terminolojisinde $\mathrm{P}_{\mathrm{d}}$ ve $\mathrm{P}_{\text {fa }}$ teorik olarak sırasıyla $\mathrm{P}\left(H_{l} \mid H_{l}\right)$ ve $\mathrm{P}\left(H_{l} \mid H_{0}\right)$ şartlı olasılık değerleri ile tanımlanmaktadır. Bu durumda test istatistiği $H_{0}$ hipotezi altında 2. Serbestlik derecesi ile merkezi Ki Kare dağılımına sahiptir. Aynı şekilde $H_{l}$ hipotezi altında ise 2. Serbestlik derecesi ile merkezi olmayan Ki Kare dağılımına sahiptir. Fakat sayısal haberleşme sistemlerinde, örneğin TV alıcılarında İşaret Gürültü Oranı (Signal to Noise Ratio-SNR) yaklaşık -20 dB seviyesinde olduğu yapılan ölçümler sonucunda bilinmektedir. Bu nedenle merkezi limit teoremi gereğince, ikincil kullanıcılar tarafından alınan işaret dağılımları Normal dağılıma yakınsamaktadır. Böylece her iki hipotez altında alınan işaret örnekleri aşağıdaki gibi ifade edilebilir.

$T_{E D} \square \begin{cases}N\left(N \sigma_{\eta}^{2}, 2 N \sigma_{\eta}^{4}\right), & H_{0} \\ N\left(N\left(\sigma_{s}^{2}+\sigma_{\eta}^{2}\right), 2 N\left(\sigma_{s}^{2}+\sigma_{\eta}^{2}\right)^{2}\right), & H_{1}\end{cases}$

Burada $\sigma_{\eta}^{2}$ ve $\sigma_{s}^{2}$ sırasıyla gürültü ve birincil kullanıcı işaretlerinin varyansını temsil etmektedir. Burumda algılama olasılığı $\left(P_{d}\right)$ aşă̆ıdaki gibi ifade edilmektedir(Shi-Qi et al., 2012).

$P_{d}=P\left(T>\gamma_{E D}\right)_{H_{1}}=Q\left(\frac{\gamma_{E D}-N\left(\sigma_{s}^{2}+\sigma_{\eta}^{2}\right)}{\sqrt{2 N\left(\sigma_{s}^{2}+\sigma_{\eta}^{2}\right)^{2}}}\right)$

Burada $Q($.), Gauss dağılım için kuyruk olasılığıdır ve aşağıdaki gibi hesaplanır.

$$
Q(x)=\frac{1}{\sqrt{2 \pi}} \int_{x}^{+\infty} \exp \left(-\frac{w^{2}}{2}\right) d w
$$

Yanlış algılama olasılığı ise teorik olarak Eşitlik 10 ile hesaplanabilir. 
$P_{f a}=P\left(T>\gamma_{E D}\right)_{H_{0}}=Q\left(\frac{\gamma_{E D}-N \sigma_{\eta}^{2}}{\sqrt{2 N \sigma_{\eta}^{4}}}\right)$

IEEE 802.11 çalışma grubu tarafında BR sistemlerinde $P_{f a}{ }^{\prime}$ nın alabileceği en yüksek değer sınırlanmıştır. Bu değer BR sistemleri için 0.1 olmalıdır. Bu durumda önceden belirlenmiş bir $P_{f a}$ değeri verildiğinde eşik değeri ise aşağıda verilmiş̧ir.

$\gamma_{E D}=F_{\chi_{2 N}^{2}}^{-1}\left(1-P_{f a}\right) \frac{\sigma_{\eta}^{2}}{2}$

Burada $F_{\chi_{2 N}^{2}}^{-1}$ serbestlik derecesi 2 olan $\chi^{2}$-dağılımlı raslantı değişkeninin olasılık dağılım fonksiyonunu tanımlamaktadır. Böylece Şekil 1 'de verilen algılama modeline göre Her bir BR kullanıcısı Eşitlik 12'de verilen kural gereği spektrum kararı verebilmektedir. Her bir BR kullanıcısının tek başına karar vermesi işbirliksiz algılamaya örnek olarak gösterilebilir.

İşbirlikli algılama modelinde ise her bir bilişsel kullanıcı, kendi yerel gözlemlerini birleşim merkezine bildirerek daha doğru bir karar verebilmek için işbirliği yapmaktadır. Bu nedenle son karar birleşim merkezinde verilmektedir. İşbirlikli algılamada kullanıcılar arasındaki uzaysal çeşitlilikten faydalanılır. Bu nedenle BR kullanıcıları arasındaki korelasyon artıkkça işbirlikli algılamanın olumlu etkileri daha fazla görülmektedir. Bant genişliği ve alınan örnek uzunluğu gibi kısıtlamalar nedeniyle, bilişsel kullanıcılar sadece sınırlı gözlemler bildirebilirler. Burada, sert birleştirme ve yumuşak birleştirme gibi iki birleşim yöntemi algoritması kullanılmaktadır. Yumuşak birleştirme yöntemi matematiksel olarak Eşitlik 12 ile ifade edilmektedir.

$$
T_{E D}=\sum_{n=1}^{N}\left|\mathbf{y}_{i}[n]\right|^{2} \frac{\sigma_{s}^{2}}{\sigma_{\eta}^{2}\left(\sigma_{s}^{2}+\sigma_{\eta}^{2}\right)}
$$

Burada $\left|y_{i}[n]\right|^{2}$, i. bilişsel kullanıcıdaki yumuşak karardır. Bu nedenle işbirlikli algılama için en verimli yöntem tüm $\mathrm{BR}$ kullanıcılarında ayrı enerji algılama kararı vermek ve verilen bu kararları Eşitlik 12'deki gibi toplamaktır.

İşbirlikçi algılamadaki diğer bir yöntem olarak bilinen sert birleştirmede ise, her bir BR kullanıcısı kendi yerel kararını vererek ve birleşim merkezine bir bit ("1" ya da " 0 ") göndermektedir. Sonraki adım ise verilen bu sert kararların birleştirilmesi ve son spektrum kararının verilmesidir. Sert birleştirme tekniğinde son kararın verilmesi için 'VE' ve 'VEYA' mantıksal kuralları kullanılmaktadır. 'VE' kuralı kullanıldığında $H_{l}$ kararı verilmesi için bütün BR kullanıcıların işareti algılamış olması gerekmektedir. 'VEYA kuralında ise sadece bir adet BR'nin' işaret algılaması $H_{l}$ kararı vermek için yeterlidir. Bu kurallar aşağıdaki gibi ifade edilmektedir.

$$
\begin{aligned}
V E \quad & \rightarrow \sum_{M} T_{m}=M \\
V E Y A & \rightarrow \sum_{M} T_{m} \geq M
\end{aligned}
$$

İşbirlikli algılama kablosuz haberleşme sistemlerinde mutlaka bulunan çok yollu sönümlenme, gürültü belirsizliği gibi bozucu faktörlere karşı, BR ve radar sistemleri için her zaman daha başarılı sonuçlar sunmaktadır.

\subsection{Adaptif Eşik Değerinin Belirlenmesi}

Eşik değerinin belirlenmesi için BR kullanıcıları tarafindan alınan işaretin kovaryans matrisinin özdeğerlerinden faydalanılmaktadır. Önerilen algılama modeline BR kullanıcı tarafından alınan işaret matrisi Eşitlik 20 ile verilmektedir. Sistemde $M$ adet BR kullanıcısı olduğu ve $N$ adet işaret örneği alındığı varsayımı ile $\mathbf{y}(n)$ matrisi $M x N$ boyutunda olacaktır.

$$
\mathbf{y}(n)=\left[\begin{array}{cccc}
y_{1,1} & y_{1,2} & \cdots & y_{1, N} \\
y_{2,1} & y_{2,2} & \cdots & y_{2, N} \\
\vdots & \vdots & \ddots & \vdots \\
y_{M, 1} & y_{M, 2} & \cdots & y_{M, N}
\end{array}\right]
$$

Burada $y_{1,1}, 1$. BR kullanıcısının algıladığı 1. örneği temsil etmektedir. Böylece matrisin her bir satırı farklı BR kullanıcısı tarafından alınan işaret örneklerini tanımlar. Bu durumda alınan işaretin kovaryans matrisi aşağıdaki gibi ifade edilebilir. 
$\Sigma_{y(n)}=\frac{1}{N} \mathbf{y}(n) \mathbf{y}(n)^{\dagger}$

Marchenko Pastur (MP) teoremine göre $\Sigma_{y(n)}$ matrisinin özdeğerleri gürültü varyansının tahmini için kullanılabilir(Yaskov, 2016).

2

Tahmin edilen gürültü varyansı $\sigma_{\eta}$ ile ifade edilirse, bu çalışmada önerilen tahmin edilmiş gürültü varyansı Eşitlik 16 ile tanımlanabilir.

$$
\sigma_{\eta}^{2}=\min _{\pi_{m}}\left(G\left(\pi_{m}\right)\right)
$$

Burada $G\left(\pi_{m}\right)$ aşağıdaki gibi ifade edilmektedir.

$$
G\left(\pi_{m}\right)=\left\|E F-m p(1-\beta) p, \pi_{m}\right\|_{2}
$$

Burada $E F$, kovaryans matrisinin özdeğerleri için deneysel/gözleme dayalı olasılık dağılım fonksiyonudur. $m p$ ise Marhenko Pastur teoremini belirlemektedir. Ayrıca $(1-\beta)$ ve $\pi_{m}$ kovaryans matrisi özdeğerlerinin $m p$ teoremi parametreleridir. Böylece önerilen adaptif eşik değeri kullanıldığında eşik değeri aşağıdaki gibi hesaplanmaktadır.

$\gamma_{E D}=F_{\chi_{2 N}^{2}}^{-1}\left(1-P_{f a}\right) \frac{\sigma_{\eta}^{2}}{2}$

Böylece adaptif enerji algılama için enerji algılama için Şekil 2'de verilen blok diyagrama bakılabilir. Burada spektrum kararı verildikten sonra sürekli eşik değeri yeniden tahmin edilerek kararın geçerliliği sınanmaktadır.

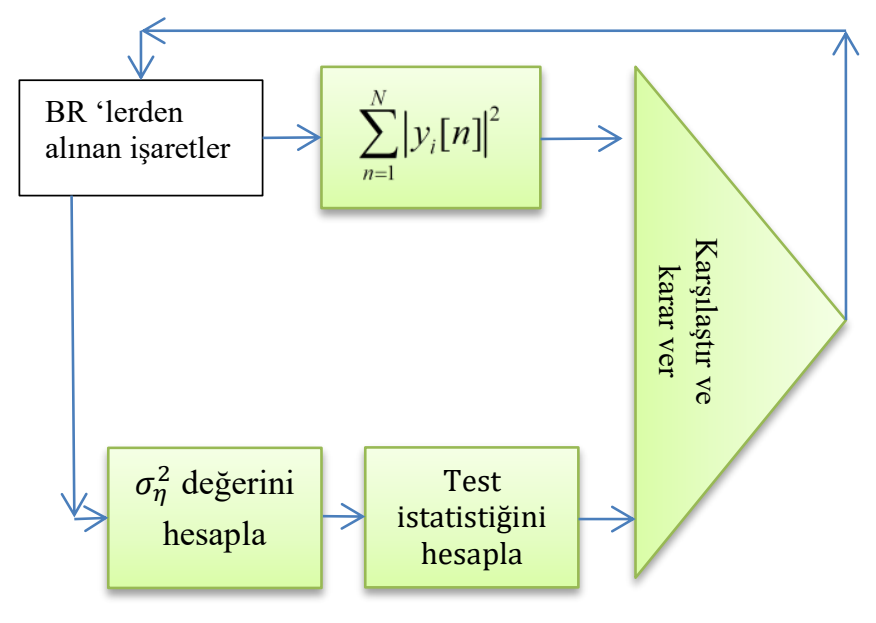

Şekil 2. Adaptif Enerji Tabalı algıalama için blok diyagram

\section{Araştırma Sonuçları ve Tartışma}

\subsection{Bulgular}

Yapılan teorik analizlerin benzetim çalışmaları için MATLAB programı kullanılmıştır. Benzetim çalışmaları Şekil 1'de verilen algılama modeli kullanılarak, birincil verici işareti rastgele olarak üretilmiştir. Spektrum algılamada eşik değeri için teorik (Eşitlik 17) ve adaptif (Eşitlik 24) ile verilen eşik değerleri kullanılmışır. Bu çalışmada önerilen yöntemin algılama performansı bakımından değerlendirilmesi için iki adet grafik şekli çizdirilmiştir. Bunlardan biri Receiver Open Characteristic (ROC) eğrileridir. ROC eğrileri radar sistemleri ve BR uygulamalarının performansının değerlendirilmesi için oldukça önemli bir yere sahiptir. Bu grafiklerde $x$ ekseni $P_{f a}, y$ ekseni ise $P_{d}$ değerini göstermektedir. Böylece bu iki değerin birlikte değişimine göre yöntem performansı 
değerlendirilmektedir. Diğer grafik türünde ise verilen SNR değerlerine göre algılama performansı değerlendirilmektedir. BR sistemlerinde gürltü ile algılama arasındaki ilişkiyi görmek açısından bu grafikler oldukça yararlı olmaktadır.

Benzetim çalışmalarından önce önerilen adaptif eşik değeri için, gürültü varyansının gerçek ve tahmin edilen değerlerini gösteren bilgiler Tablo 1. ile verilmektedir. Burada gerçek gürültü gücü ile tahmin edilen gürültü gücünü farklı SNR değerlerine göre göstermektedir. Tablodan görüldüğü üzere bu çalışmada kullanılan hesaplama yöntemi ile, çok yüksek gürültü seviyelerinde hata oranı daha fazladır. Ayrıca gerçek gürültü seviyesi $\left(\sigma_{\eta}^{2}\right)$ negatif değerlerde iken, tahmin edilen gürültü seviyesi $\left(\sigma_{\eta}^{2}\right)$ daha fazla bulunmuş̧ur. Bu durum gerçek gürültü seviyesi pozitif olduğunda tersine döndüğü görülmektedir.

Tablo 1. Gerçek ve Tahmin Edilen Gürültü Seviyeleri

\begin{tabular}{|c|c|}
\hline$\sigma_{\eta}^{2}(\mathrm{~dB})$ & $\sigma_{\eta}^{2}(\mathrm{~dB})$ \\
\hline-20 & $-18,5$ \\
\hline-15 & $-13,4$ \\
\hline-10 & $-9,1$ \\
\hline 0 & 1,2 \\
\hline 5 & 6,4 \\
\hline
\end{tabular}

Şekil 3 ‘de 5 dB gürültü ve 4 adet BR kullanıısı olduğu varsayımı ile işbirliksiz algılama sonuçları verilmektedir. Bu nedenle verilen grafikte her bir BR kullanıcısının verdiği sert karar görülmektedir. $P_{f a}$, uluslar arası haberleşme komitesinin belirlediği sınır değer 0.1 seçilmiştir. Bu bilgilere ek olarak bu grafikler Monte Carlo analizi yapılmış olup, önerilen yöntem 100 kere çalıştırılmış ve $P_{d}$ 'nin ortalaması alınmıştır. SIMO kanal için ise kanal katsayıları yine rastgele üretilmiştir. Algılama değerlerinin birbirine oldukça yakın olduğu görülmektedir. Bu durumun en önemli sebebi BR kullanıcılarının algıladığı işaretlerin, birbirleri ile olan ilinti derecesidir. Uygulamada BR kullanıcıları birbirlerine ne kadar yakın olursa, anten ilintileri o kadar fazla olacağından algılama değerleri birbirine yakınsayacaktır. Fakat uygulama da bu durumun önüne geçmek için BR kullanıcılarının birbiri ile yeterince uzakta olması gerekmektedir.

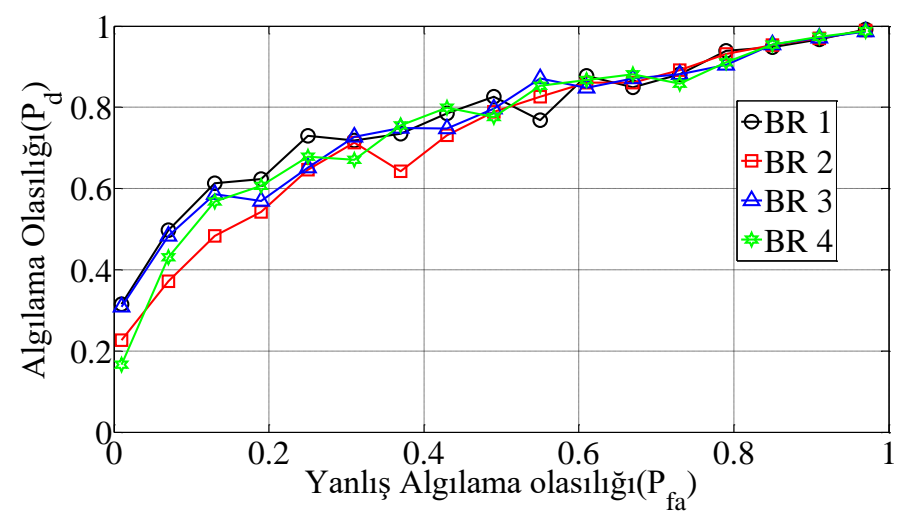

Şekil 3. $N=10^{\wedge} 4, S N R=5 d B, M=4$ için ROC Ĕgrileri

Şekil 4'de ise $0 \mathrm{~dB}$ gürültü varlığında ROC eğrilerini göstermektedir. Görüldüğü üzere gürülttü seviyesinin azalması BR kullanıcılarının algılama olasılığı değerlerinde gözle görülür bir artış sağlamıştır.

İşbirlikli algılama için VE kuralına göre sert birleştirme yapıldığında algılama performansları Şekil 5 ile verilmektedir. Burada görüldüğü üzere gürülttü varyansı $0 \mathrm{~dB}$ ile $20 \mathrm{~dB}$ arasında değiştirilmiştir. Bu grafik için (geleneksel) sonuçlar adaptif olmayan EA tabanlı spektrum algılama için benzetim sonuçlarını göstermektedir. Adaptif olanlar ise Şekil 2 ile verilen blok diyagrama göre EA tabanlı spektrum algılama sonuçlarını göstermektedir. Grafikten anlaşılacağı üzere aynı gürültü seviyesi için geleneksel ve adaptif algılama yöntemlerinde arasında gözle görülür bir performans farkı oluşmaktadır. Bunun en önemli sebebi gürültü varyansının tahmininde oluşan farklılıklardır. 


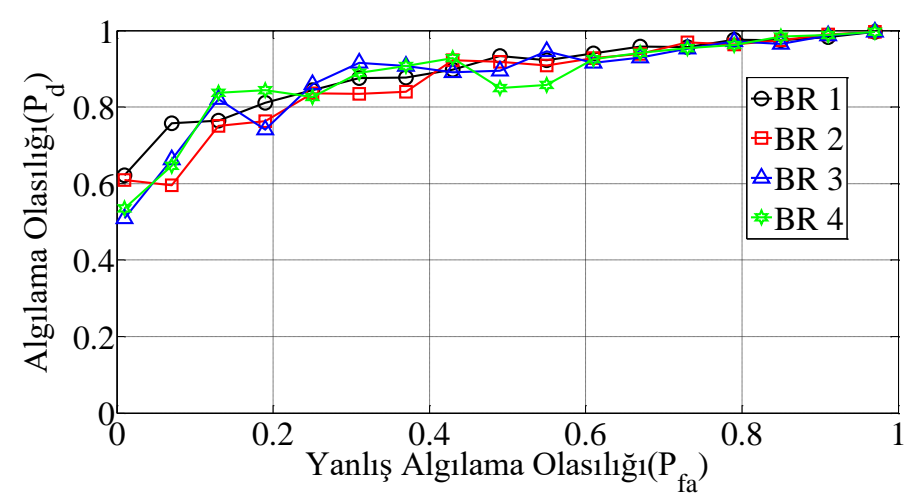

Şekil 4. $N=10^{\wedge} 4, S N R=0 d B$ için ROC Ĕgrileri

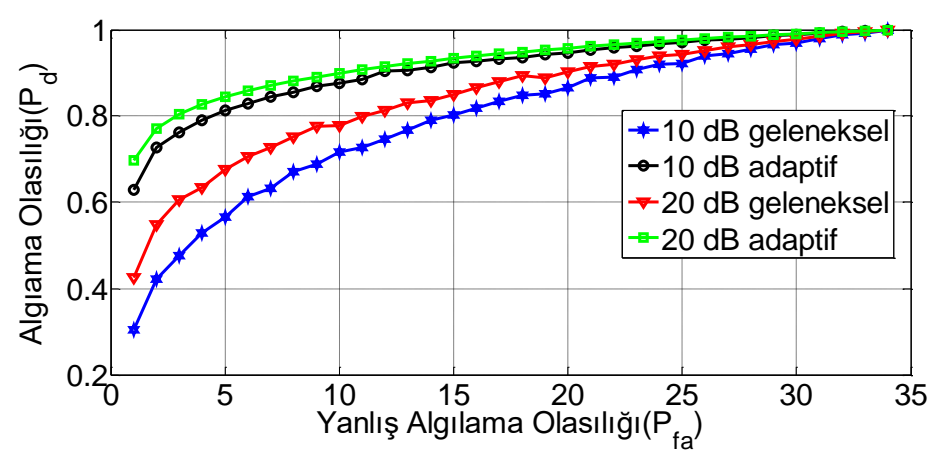

Şekil 5. Yumuşak Birleştirme için ROC Ĕgrileri, $N=10^{\wedge} 4, P_{f a}=0.1=5 \mathrm{~dB}, M=4$

Şekil 6'da ise işbirlikli ve işbirliksiz algılama için algılama performansları verilmektedir. Bu grafik için en iyi algılama performansı İşbirlikli ve adaptif eşik değeri kullanan yöntem olduğu görülmektedir(Şekil 6 da geleneksel algılama sonuçlarına yer verilmemiştir). Ayrıca bu grafikte verilen $\mathrm{dB}$ değerleri gürültü belirsizliği faktörünü tanımlamaktadır. Gürültü belirsizliği faktörü bilindiği üzere kablosuz haberleşme sistemlerinde sürekli bulunan ve haberleşme kalitesini olumsuz yönde etkileyen bir faktördür. Çalışmanın giriş bölümünde de bahsedildiği gibi, EA tabanlı yöntemler gürültü belirsizliğine karşı oldukça kırılgandırlar. Bu nedenle benzetim sonuçlarında bu grafiğe de yer verilmektedir.

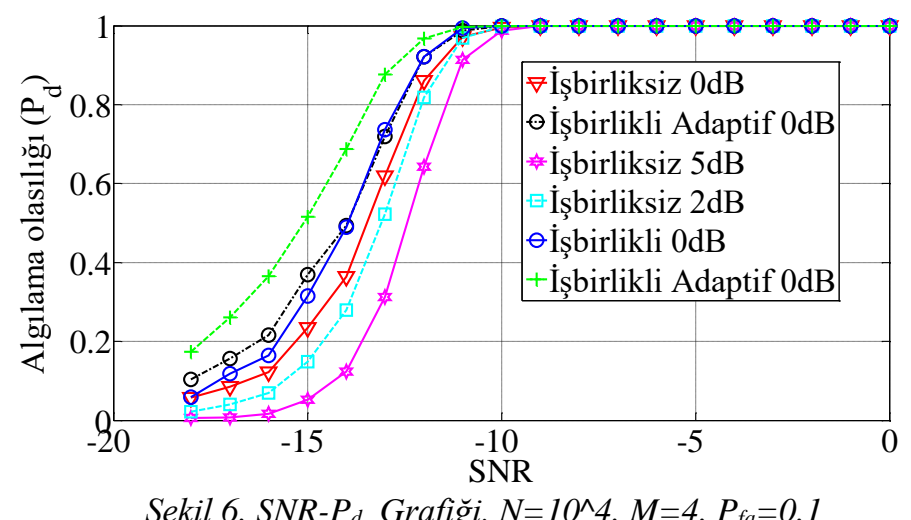

\section{Sonuç}

Bu çalışmada BR sistemleri için başlangıç adımı konumunda olan, EA tabanlı spektrum algılama yöntemi incelenmiştir. EA tabanlı algılama yöntemi, gürültü belirsizliğine olan aşırı kırılganlığı ile yüksek gürültü seviyelerinde başarısız sonuçlar sergileyebilmektedir. $\mathrm{Bu}$ nedenle EA tabanlı algılama yönteminin spektrum algılayabilme başarısı, ortamda bulunan gürültü seviyesinin bilinmesi ile doğru orantılı değişmektedir. Bu çalışmada ortamda bulunan gürültüyü varyansının tahmini için Marchenko Pastur teoremine dayalı bir kestirim yöntemi önerilmektedir. Bu yöntemle EA tabanlı algılama için adaptif bir algılama yöntemi kullanılmaktadır. Yapılan benzetim çalışmaları işbirlikli ve işbirliksiz olarak değerlendirilmektedir. Benzetim çalışmalarından alınan sonuçlara göre önerilen algılama modeli geleneksel yönteme göre performans artı̧ı sağlamaktadır. 


\section{Kaynakça}

Abdalrazik, A., Soliman, H., Abdelkader, M. F., \& Abuelfadl, T. M. (2016). Power performance enhancement of underlay spectrum sharing using microstrip patch ESPAR antenna. Advances in Electrical and Computer Engineering, 2016-Septe(1), 61-68. https://doi.org/10.1109/WCNC.2016.7565095

Ahmad, A. W., Yang, H., \& Lee, C. (2015). Maximizing throughput with wireless spectrum sensing network assisted cognitive radios. International Journal of Distributed Sensor Networks, 2015, 1-10. https://doi.org/10.1155/2015/195794

Charan, C., \& Paney, R. (2016). Eigenvalue based double threshold spectrum sensing under noise uncertainty for cognitive radio. Optik, 127(15), 5968-5975. https://doi.org/10.1016/j.ijleo.2016.04.049

Çiflikli, C., \& Ilgin, F. Y. (2018). Covariance Based Spectrum Sensing with Studentized Extreme Eigenvalue. Technical Gazette, 25(6), 100-106.

Commission, F. C. (2002). Revision of Part 15 of the Commission's Rules Regarding Ultra-Wideband Transmission Systems. First Report and Order in ET .... https://doi.org/10.1017/CBO9781107415324.004

Dahlman, E., Parkvall, S., \& Skold, J. (2013). 4G: LTE/LTE-Advanced for Mobile Broadband. 4G: LTE/LTE-Advanced for Mobile Broadband. https://doi.org/10.1016/C2013-0-06829-6

De Vito, L. (2013). Methods and technologies for wideband spectrum sensing. Measurement: Journal of the International Measurement Confederation, 46(9), 3153-3165. https://doi.org/10.1016/j.measurement.2013.06.013

Dibal, P. Y., Onwuka, E. N., Agajo, J., \& Alenoghena, C. O. (2018). Application of wavelet transform in spectrum sensing for cognitive radio: A survey. Physical Communication, 28, 45-57. https://doi.org/10.1016/j.phycom.2018.03.004

Edelman, A. (2005). Random matrix theory. Acta Numerica, 1-65. https://doi.org/10.1017/S0962492904000236

Erpek, T., Steadman, K., \& Jones, D. (2007). CR..2 A..Spectrum Occupancy Measurements: Dublin Ireland Collected On April 16-18 , 2007. In Technical Report, Shared Spectrum Company Nov 2007 (pp. 1-34). Vienna: Shared Spectrum Company.

He, Y., Ratnarajah, T., Yousif, E. H. G., Xue, J., \& Sellathurai, M. (2016). Performance analysis of multi-antenna GLRT-based spectrum sensing for cognitive radio. Signal Processing, 120, 580-593. https://doi.org/10.1016/j.sigpro.2015.10.018

Kortun, A., Ratnarajah, T., Sellathurai, M., Zhong, C., \& Papadias, C. B. (2011). On the performance of eigenvalue-based cooperative spectrum sensing for cognitive radio. IEEE Journal of Selected Topics in Signal Processing, 5(1), 49-55. https://doi.org/10.1109/JSTSP.2010.2066957

Kortun, Ayse, Ratnarajah, T., Sellathurai, M., Liang, Y. C., \& Zeng, Y. (2014). On the eigenvalue-based spectrum sensing and secondary user throughput. IEEE Transactions on Vehicular Technology, 63(3), 1480-1486. https://doi.org/10.1109/TVT.2013.2282344

Li, C. M., \& Lu, S. H. (2016). Energy-Based Maximum Likelihood Spectrum Sensing Method for the Cognitive Radio. Wireless Personal Communications, 89(1), 289-302. https://doi.org/10.1007/s11277-016-3266-0

Lu, L., Li, G. Y., Swindlehurst, A. L., Ashikhmin, A., \& Zhang, R. (2014). An overview of massive MIMO: Benefits and challenges. IEEE Journal on Selected Topics in Signal Processing, 8(5), 742-758. https://doi.org/10.1109/JSTSP.2014.2317671

Luo, X., Wang, X., Zhang, M., \& Guan, X. (2019). Distributed detection and isolation of bias injection attack in smart energy grid via interval observer. Applied Energy, 256, 113703. https://doi.org/10.1016/J.APENERGY.2019.113703

Mitola, J. (2006). Cognitive Radio Architecture. In Cognitive Radio Technology (pp. 435-500). Newnes. https://doi.org/10.1016/B978-075067952-7/50015-5

Mitola, J., \& Maguire, G. Q. (2001). Cognitive radio: Making software radios more personal. In Software Radio Technologies: Selected Readings. https://doi.org/10.1109/9780470546444.ch4

Mohammadi, A., Javadi, S. H., Ciuonzo, D., Persico, V., \& Pescapé, A. (2019). Distributed detection with fuzzy censoring sensors in the presence of noise uncertainty. Neurocomputing. https://doi.org/10.1016/j.neucom.2019.03.044

Pillay, N., \& Xu, H. J. (2012). Blind eigenvalue-based spectrum sensing for cognitive radio networks. IET Communications, 6(11), 1388. https://doi.org/10.1049/iet-com.2011.0506

S, A. P., \& Jayasheela, M. (2012). Cyclostationary feature detection in cognitive radio using different modulation schemes. International Journal of Computer Applications, 47(21), 975-8887. https://doi.org/10.7763/IJFCC.2013.V2.249

Shi-Qi, L., Bin-Jie, H., \& Xian-Yi, W. (2012). Hierarchical cooperative spectrum sensing based on double thresholds energy detection. Communications Letters, IEEE, 16(7), 1096-1099. https://doi.org/10.1109/LCOMM.2012.050112.120765

Szczerba, K., Westbergh, P., Agrell, E., Karlsson, M., Andrekson, P. A., \& Larsson, A. (2013). Comparison of intersymbol interference power penalties for OOK and 4-PAM in short-range optical links. Journal of Lightwave Technology, 31(22), 3525-3534. https://doi.org/10.1109/JLT.2013.2285468

Verma, P., \& Singh, B. (2016). Overcoming sensing failure problem in double threshold based cooperative spectrum sensing. Optik, 127(10), 4200-4204. https://doi.org/10.1016/j.ijleo.2016.01.108

Yaskov, P. (2016). A short proof of the Marchenko-Pastur theorem. Comptes Rendus Mathematique, 354(3), 319-322. https://doi.org/10.1016/J.CRMA.2015.12.008

Yonghong Z., Ying-Chang L., \& Rui Z. (2008). Blindly combined energy detection for spectrum sensing in cognitive radio. IEEE Signal Processing Letters, 15(1), 649-652. https://doi.org/10.1109/LSP.2008.2002711

Zeng, Y., \& Liang, Y. C. (2009). Eigenvalue-based spectrum sensing algorithms for cognitive radio. IEEE Transactions on Communications, 57(6), 1784-1793. https://doi.org/10.1109/TCOMM.2009.06.070402 